\section{Serum Adiponectin} Levels are Associated with Microcirculatory Function, but not with Coronary Artery Disease in the Young

Dear Sir, Adiponectin is secreted in mature adipocytes, has a role in diabetes and obesity and has been studied in coronary artery disease (CAD), considered cardioprotective, ${ }^{[1]}$ what is nonetheless controversial. ${ }^{[2,3]}$ The assessment of systemic microvascular reactivity is useful for the evaluation of cardiovascular diseases, and laser speckle contrast imaging (LSCI) is an innovative approach, using the cutaneous microcirculation as a representative vascular bed. ${ }^{[4]}$ We evaluated serum adiponectin levels in early-onset CAD (EOCAD) patients and age-matched controls, as well as their association with microvascular function assessed by LSCI. EOCAD was defined as any obstruction $\geq 50 \%$ on coronary angiography, prior myocardial infarction, or myocardial revascularization in patients $\leq 45$ years. Patients with acute coronary syndromes or interventions for $<6$ months were not included in the study. Controls were adults $\leq 45$ years without CAD or cardiac symptoms. After a 12-h fast, venous blood was collected. Adiponectin was measured in serum by ELISA (Human High Molecular Weight Adiponectin, Millipore, Missouri, USA). Cutaneous microvascular reactivity was evaluated using LSCI (PeriCam; Perimed, Sweden), as previously described ${ }^{\left[{ }^{[5]}\right.}$ using transdermal iontophoretic delivery of acetylcholine (ACh) or sodium nitroprusside (NPS). Perfusion changes were measured in arbitrary perfusion units and expressed as peak values, representing the maximal vasodilation observed, and area under the curve of vasodilation. The study complied with the 1964 Declaration of Helsinki and its amendments and was approved by the local ethics committee. Informed written consent was obtained from all participants. Categorical variables were expressed as $n(\%)$ and compared with Chi-square. Continuous variables were expressed as a mean \pm standard deviation or median/ interquartile range, compared with Mann-Whitney's test. Correlations were evaluated with Spearman's test. A value of $P<0.05$ was considered statistically significant.

Twenty-five EOCAD patients (age $42.8 \pm 2.0$ years, $60 \%$ male, $88 \%$ hypertensive, $28 \%$ diabetic, $56 \%$ obese) and

\begin{tabular}{lc}
\hline $\begin{array}{l}\text { Table 1: Significant }(\boldsymbol{P}<0.05) \\
\text { adiponectin, clinical and microcirculatory variables }\end{array}$ \\
\hline & Spearman's coefficient \\
\hline Body mass index & -0.38 \\
HDL-cholesterol & 0.41 \\
ACh-induced peak vasodilatation (APU) & 0.51 \\
Area under the curve of ACh-induced & 0.53 \\
vasodilatation (APU) & \\
NPS-induced peak vasodilatation (APU) & 0.61 \\
Area under the curve of NPS-induced & 0.56 \\
vasodilatation (APU) & \\
\hline ACh: Acetylcholine, APU: Arbitrary perfusion units, HDL: High-density lipoprotein, \\
NPS: Sodium nitroprusside
\end{tabular}

25 controls $(41.1 \pm 3.4$ years, $44 \%$ male; $0,4 \%$ and $24 \%$, respectively) were studied. Patients had higher body mass index (BMI) $\left(31.7 \pm 5.8\right.$ vs. $\left.26.2 \pm 3.5 \mathrm{~kg} / \mathrm{m}^{2}, P<0.05\right)$, glucose $(115.0 \pm 31.0$ vs. $93.5 \pm 13.3 \mathrm{mg} / \mathrm{dl}, P<0.05)$ and triglycerides (164.0 [46.0-52.0] vs. 91.0 [42.0-242.0] mg/dl, $P<0.05$ ), and lower high-density lipoprotein (HDL)-cholesterol $(36.6 \pm 7.1$ vs. $43.9 \pm 10.2 \mathrm{mg} / \mathrm{dl}, P<0.05)$. Serum adiponectin was not significantly different between patients and controls (19.7 [9.0-57.0] vs. $24.3[4.0-59.0] \mu \mathrm{g} / \mathrm{ml})$. There was a trend toward lower adiponectin levels in obese than in nonobese (18.1 [9-34] vs. $25.1[4-59] \mu \mathrm{g} / \mathrm{ml}, P=0.07)$. Significant correlations between adiponectin and other variables are shown in Table 1. There was an inverse correlation between adiponectin and BMI, and positive correlations between adiponectin and HDL-cholesterol, as well as ACh-induced and NPS-induced vasodilation.

In conclusion, both endothelium-dependent and endothelium-independent vasodilatation were positively correlated with adiponectin levels, what reinforces the vasoprotective effect of adiponectin. The absence of difference of adiponectin levels among patients and controls may be attributed to the small sample size. To the best of our knowledge, this is the first study to use LSCI show the association between adiponectin and microcirculatory function. Further larger studies are needed to increase this knowledge.

\section{Acknowledgment}

This work was supported by Foundation for the Support of Research in Rio de Janeiro.

\section{Financial support and sponsorship}

This work was supported by Foundation for the Support of Research in Rio de Janeiro.

\section{Conflicts of interest}

There are no conflicts of interest. De Lorenzo $\mathrm{A}^{1,2}$, Moreira $\mathrm{ASB}^{1}$, Guimaraes $\mathrm{E}^{2}$,
Oliveira $\mathrm{GMM}^{2}$, Maia $\mathrm{E}^{1}$, Tibirica $\mathrm{EV}^{1,3}$ 
${ }^{1}$ Department of Education and Research, Instituto Nacional de Cardiologia, ${ }^{2}$ Department of Cardiology, Universidade

Federal do Rio de Janeiro, ${ }^{3}$ Cardiovascular Integration Nucleus, Instituto Oswaldo Cruz, Rio de Janeiro, Brazil E-mail:andlorenzo@hotmail.com

\section{References}

1. Lee S, Kwak HB. Role of adiponectin in metabolic and cardiovascular disease. J Exerc Rehabil 2014;10:54-9.

2. Hashimoto N, Kanda J, Nakamura T, Horie A, Kurosawa H, Hashimoto $\mathrm{T}$, et al. Association of hypoadiponectinemia in men with early onset of coronary heart disease and multiple coronary artery stenoses. Metabolism 2006;55:1653-7.

3. Wang Y, Zheng A, Yan Y, Song F, Kong Q, Qin S, et al. Association between HMW adiponectin, HMW-total adiponectin ratio and early-onset coronary artery disease in Chinese population. Atherosclerosis 2014;235:392-7.

4. Roustit M, Millet C, Blaise S, Dufournet B, Cracowski JL. Excellent reproducibility of laser speckle contrast imaging to assess skin microvascular reactivity. Microvasc Res 2010;80:505-11.
5. Souza EG, De Lorenzo A, Huguenin G, Oliveira GM, Tibiriçá E. Impairment of systemic microvascular endothelial and smooth muscle function in individuals with early-onset coronary artery disease: Studies with laser speckle contrast imaging. Coron Artery Dis 2014;25:23-8.

This is an open access article distributed under the terms of the Creative Commons Attribution-NonCommercial-ShareAlike 3.0 License, which allows others to remix, tweak, and build upon the work non-commercially, as long as the author is credited and the new creations are licensed under the identical terms.

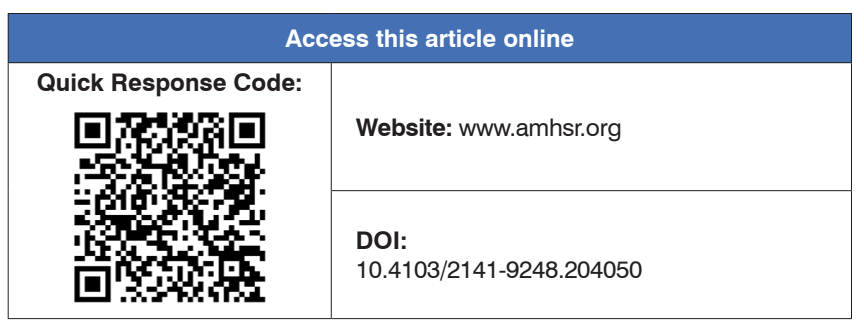

How to cite this article: De Lorenzo A, Moreira A, Guimaraes E, Oliveira G, Maia E, Tibirica EV. Serum adiponectin levels are associated with microcirculatory function, but not with coronary artery disease in the young. Ann Med Health Sci Res 2016;6:332-3. 